\title{
Differences in home food availability of high- and low-fat foods after a behavioral weight control program are regional not racial
}

\author{
Rebecca A Krukowski ${ }^{*}$, Jean Harvey-Berino ${ }^{2}$, Delia Smith West $^{1}$
}

\begin{abstract}
Background: Few studies, if any, have examined the impact of a weight control program on the home food environment in a diverse sample of adults. Understanding and changing the availability of certain foods in the home and food storage practices may be important for creating healthier home food environments and supporting effective weight management.

Methods: Overweight adults ( $n=90 ; 27 \%$ African American) enrolled in a 6-month behavioral weight loss program in Vermont and Arkansas. Participants were weighed and completed measures of household food availability and food storage practices at baseline and post-treatment. We examined baseline differences and changes in high-fat food availability, low-fat food availability and the storage of foods in easily visible locations, overall and by race (African American or white participants) and region (Arkansas or Vermont).
\end{abstract}

Results: At post-treatment, the sample as a whole reported storing significantly fewer foods in visible locations around the house $(-0.5 \pm 2.3$ foods), with no significant group differences. Both Arkansas African Americans $(-1.8 \pm$ 2.4 foods) and Arkansas white participants (-1.8 \pm 2.6 foods) reported significantly greater reductions in the mean number of high-fat food items available in their homes post-treatment compared to Vermont white participants $(-0.5 \pm 1.3$ foods), likely reflecting fewer high-fat foods reported in Vermont households at baseline. Arkansas African Americans lost significantly less weight $(-3.6 \pm 4.1 \mathrm{~kg})$ than Vermont white participants $(-8.3 \pm 6.8 \mathrm{~kg})$, while Arkansas white participants did not differ significantly from either group in weight loss $(-6.2 \pm 6.0 \mathrm{~kg})$. However, home food environment changes were not associated with weight changes in this study.

Conclusions: Understanding the home food environment and how best to measure it may be useful for both obesity treatment and understanding patterns of obesity prevalence and health disparity.

\section{Background}

In recent years, efforts to understand the obesity crisis have focused attention on measuring and understanding the role of the "built environment" (i.e., the physical surroundings that may impact dietary intake or energy expenditure, including homes [1]). Many experts now agree that the built environment must be considered in any effort to understand or reduce obesity [2]. Research has begun emerging on possible associations between the home food environment and food intake [3-8]. Studies have found a relationship between number of high-

\footnotetext{
* Correspondence: RAKrukowski@uams.edu

${ }^{1}$ Fay W. Boozman College of Public Health, University of Arkansas for Medical Sciences, Little Rock, AR, USA

Full list of author information is available at the end of the article
}

fat foods in the home and fat intake [5] and fruit and vegetable availability in the home and intake of these foods among adolescents $[4,6,7]$. Understanding home food availability is crucial in fully grasping overall patterns of dietary intake, as Nielsen and colleagues [9] estimated that $65 \%$ of all calories were consumed in the home.

Few studies, however, have examined the impact of a behavioral weight control program on the home food environment of adults $[10,11]$, and no studies have examined whether home environment characteristics change over the course of a weight control program in distinct ways for different race groups or in different regions. Ample evidence exists to document differential response to weight loss programs by race [12-15], with 
African Americans tending to lose less weight than white participants. There is also some suggestion that individuals from different regions of the United States may respond differently to similar weight loss programs, due to higher initial body weight $[16,17]$ or greater initial dietary fat intake $[18,19]$.

Changes in availability of higher fat foods in the home and food storage practices may be important for supporting weight management efforts. Targeting fat intake in addition to overall caloric intake in a behavioral weight control program is strongly supported by studies $[20,21]$ that demonstrate when fat and calories are both controlled, weight loss is improved. Furthermore, some initial evidence suggests an association between successful weight loss and significant changes in the home food environment [10]. Such changes in the food environment within the home may even facilitate weight loss among individuals in the household who are not directly engaged in a weight control intervention program [10]. Thus, parameters associated with healthy changes in the home food environment may be a promising avenue for direct intervention, supporting weight management efforts and promoting healthier dietary intake in general. There is some evidence that the broader food environment differs for African Americans compared with Caucasians [22-24], and it is likely that the broader food environment differs between regions due to greater rural areas in the southern portion of the United States [25]. However, even though the home environment is likely influenced by neighborhood disparities in food availability [3], there have been no explorations to date of regional or racial influences on more immediate home food environments.

The current study prospectively examined changes in food availability and storage of foods in the homes of individuals enrolled in a behavioral weight loss program over six months. Specifically, we examined changes in high-fat food availability, low-fat food availability and the storage of foods in visible locations, overall and by race (African American or white participants) and region (Arkansas or Vermont). We also explored whether changes in the home food environment were related to weight loss achieved in the behavioral weight control program. Examining the home food environment following a weight control program may help to understand the process of lifestyle changes that may be associated with successful weight loss, as well as possible cultural factors (i.e., race and/or region) that may influence these changes.

\section{Methods}

\section{Participants}

Participants were recruited in 2007-2008 for a behavioral weight loss research program through community-based efforts such as presentations, flyers, and social networking and targeted mailings over the Internet. Interested participants completed an online screening and two in-person assessments prior to randomization. Eligibility criteria included overweight (body mass index [BMI] between 25 and $50 \mathrm{~kg} / \mathrm{m}^{2}$ ), generally healthy and able to walk for exercise. Individuals were considered ineligible if they were younger than 18 years, had medical conditions that contraindicated participation in a behavioral weight loss program containing an exercise component, were pregnant or lactating, or were enrolled in another weight reduction program. Participants lived within 45 minutes by car of Little Rock, Arkansas or Burlington, Vermont. These regions encompass a mix of urban, suburban, and rural areas. Individuals enrolled in the final wave of recruitment $(\mathrm{N}=90)$ for a larger randomized controlled trial were eligible for this ancillary study. All participants received the same 6-month behavioral weight control program. The study was approved by the Committee on Human Research in the Behavioral Sciences at the University of Vermont and the Institutional Review Board at the University of Arkansas for the Medical Sciences.

\section{Measures}

Participants completed assessments including the following measures at baseline and after 6 months of a behavioral weight control program:

\section{Demographic Characteristics}

Participants reported their gender, age, education and race.

\section{Weight and Height}

Participants were weighed in street clothes without shoes on a calibrated digital scale. Height was assessed using a wall-mounted stadiometer. BMI was calculated as weight $(\mathrm{kg}) /$ height $(\mathrm{m})^{2}$.

\section{Household Food Environment}

The Household Food Inventory [8,10,11] was used to quantify household food availability based on 26 common food categories that included 14 high-fat food categories (> 45\% calories from fat) (e.g., cheese, cookies, beef/pork/ lamb) and 12 low-fat food categories $(<18 \%$ calories from fat) (e.g., broccoli, tomatoes/tomato juice [including pico de gallo], apples/applesauce/pears). Participants were instructed to "check all places where food might be stored and indicate whether each food category was available regardless of the amount on that day." Previous research has found good test-retest reliability (Pearson $r$ correlations $>0.70$ ) [8] and inter-rater reliability (i.e., concordance with spouse) [10] for this measure. Furthermore, Raynor and colleagues [8] found a strong association between the availability of food items on this measure and dietary fat intake. The measure has been used previously in an ethnically-diverse population with subjects from both northern and southern regions of the 
United States and was demonstrated in that study to be correlated with actual dietary intake, as well as sensitive to changes in the home food environment following a behavioral weight control program [10]. To further characterize the home food environment, the Food Storage Questionnaire [26] was used to assess food storage practices in the home. Participants were instructed to "look around their homes, without opening any cabinets, drawers, the refrigerator, or the freezer, and indicate whether foods from 11 categories of healthier and less healthy foods (e.g., dried fruits, chocolate, nuts and seeds, pie) were stored in readily visible locations (e.g., on countertops, kitchen table, living room coffee table)." At baseline only, participants were asked to indicate how many days it had been since their last food shopping trip.

\section{Intervention}

A comprehensive behavioral weight loss program targeting dietary restriction and physical activity promotion, as well as behavioral strategies to achieve the diet and activity change recommendations, was offered to all participants over 24 weekly one-hour group sessions. All sessions were delivered by a trained facilitator with expertise in conducting behavioral weight control interventions and were based on empirically established programs [27-29]. Participants were instructed to strive for a weight loss of $7 \%$ or more of initial weight. They were given a daily calorie and fat intake goal to help them achieve this weight loss. Weekly aerobic exercise goals progressed from 50 to 200 minutes over nine weeks and remained at 200 minutes weekly thereafter. Behavioral strategies introduced to facilitate and support recommended habit changes included goal setting, problem solving, reducing food cues, and self monitoring. However, home food environment changes were only a minor aspect of the program and included recommendations to remove visible food cues from the home by storing foods out of sight, to increase the availability of low calorie, low-fat foods readily accessible in the house and to modify grocery shopping behaviors. Participants were asked to self monitor daily dietary intake and physical activity, as well as to weigh themselves daily. Self monitoring was reviewed by the facilitator and written feedback was provided on a weekly basis. A high rate of adherence to the study goals of attendance and selfmonitoring were achieved: participants submitted 73\% of self-monitoring journals and attended an average of $69 \%$ of their group meetings [30].

\section{Analysis}

Repeated measures t-tests were used to examine overall changes over the treatment period in home food environment variables. Race and region-based group differences (i.e., three groups- Arkansas African American participants, Arkansas white participants, Vermont white participants) in baseline weight and weight change over treatment were examined using analysis of variance (ANOVA). Post-hoc comparisons were conducted using Tukey's HSD test. In addition, race and region-based group differences were examined using between-groups analysis of covariance (ANCOVA), controlling for baseline weight. Between-groups ANCOVA was also used to assess the group differences in the impact of a behavioral weight control program on the home food environment, controlling for weight change over the treatment period. Relationships between home food environment variables and baseline weight and weight change were examined using Pearson correlations. In addition, Pearson correlation were used to examine the relationship between baseline home food environment and the number of days since the participant had last gone food shopping. To account for participants who were missing some or all data at the post-treatment data collection visit $(n=16)$, baseline observation was carried forward (i.e., baseline value was inserted for the post-treatment value). This method is preferred for interpolating weight change data [31]. Data were analyzed using SPSS 16.0, using a significance level of 0.05 .

\section{Results}

Participants $(\mathrm{n}=90)$ were predominantly obese (BMI range: $27.7-49.1$ ), with a mean age of 44.6 years (range: 18 - 65 years) and were $95 \%$ female, with $73 \%$ self identifying as white and $27 \%$ as African American (Table 1). All of the African American participants were enrolled from Arkansas. The racial proportions of the sample recruited in Arkansas were 54\% African American and $46 \%$ white. The majority of the participants in the study $(65 \%)$ had at least a college degree. Significantly more Arkansas African Americans (69\%) and Vermont white participants (69\%) had at least a college degree as compared to the Arkansas white participants (50\%). There was a statistically significant difference in baseline weight for the three race- and region-based groups. Post-hoc comparisons indicated that Arkansas African Americans were significantly heavier than Vermont white participants. Arkansas white participants did not differ significantly from either the Arkansas African Americans or the Vermont white participants in baseline weight. There were no significant differences in age and proportion female between the race and regionbased groups.

There were no significant baseline differences between Arkansas African Americans, Arkansas white participants, and Vermont white participants in baseline food storage practices in the home (see Table 1). However, there were significant differences between the three groups in the number of high-fat food availability in the 
Table 1 Baseline Demographic and Unadjusted Home Food Environment Characteristics*

\begin{tabular}{|c|c|c|c|c|c|}
\hline & $\begin{array}{l}\text { Overall } \\
\mathrm{N}=90\end{array}$ & Vermont White participants $N=44$ & $\begin{array}{r}\text { Arkansas White } \\
\text { participants } \\
N=21 \\
\end{array}$ & $\begin{array}{r}\text { Arkansas African } \\
\text { American } \\
\mathrm{N}=25\end{array}$ & p-value \\
\hline Age (years) & $44.6 \pm 10.2$ & $46.2 \pm 10.2$ & $42.7 \pm 11.4$ & $41.7 \pm 2.5$ & $p>0.05$ \\
\hline Female (\%) & $95 \%$ & $93 \%$ & $96 \%$ & $100 \%$ & $p>0.05$ \\
\hline College Education or Higher (\%) & $65 \%$ & $69 \%$ & $50 \%$ & $69 \%$ & $p<0.05$ \\
\hline Weight (kg) & $98.3 \pm 19.0$ & $94.0 \pm 20.3$ & $98.0 \pm 13.5$ & $106.0 \pm 18.8$ & $p<0.05$ \\
\hline Food Storage (FSQ ${ }^{a}$ food categories) & $3.6 \pm 2.5$ & $3.2 \pm 2.2$ & $3.7 \pm 2.1$ & $4.1 \pm 3.1$ & $p>0.05$ \\
\hline Low-Fat Foods (HFI food categories) & $7.2 \pm 2.1$ & $7.6 \pm 1.9$ & $6.4 \pm 2.1$ & $7.0 \pm 2.1$ & $p=0.075$ \\
\hline High-Fat Foods (HFI food categories) & $8.5 \pm 2.5$ & $7.6 \pm 2.0$ & $9.4 \pm 3.0$ & $9.2 \pm 2.5$ & $p<0.01$ \\
\hline
\end{tabular}

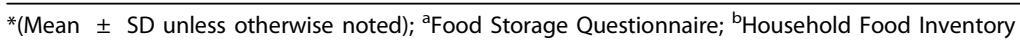

home at baseline. Post-hoc comparisons indicate that the mean number of high-fat foods that the Vermont white participants reported was significantly lower than both the mean number of household high-fat foods reported by both Arkansas white participants and Arkansas African American participants. There was a marginally significant difference between the groups in the number of low-fat foods in the home, such that there was a non-significant trend for Vermont white participants to have more low-fat foods in their homes than both the Arkansas white participants or African American participants, with no difference between Arkansas groups. To account for baseline differences in weight of the three race- and region-based groups, the baseline analyses for the food environment variables (availability and storage) were repeated using an ANCOVA to adjust for baseline weight. Similar results were found, so unadjusted values are presented in Table 1. There was no significant relationship between any of the baseline home food environment variables and the number of days since the last food shopping trip. No significant correlation was observed between baseline self-report of any of the home food environment measures and baseline weight in the sample as a whole or within any of the race-region groups.

At post-treatment, there was a statistically significant difference in weight loss across the three groups. Posthoc comparisons indicated that Arkansas African Americans lost significantly less weight than Vermont white participants. Arkansas white participants had intermediate weight loss outcomes which did not differ significantly from either the Arkansas African Americans or the Vermont white participants (Table 2).

At post-treatment, the sample as a whole reported storing significantly fewer foods in visible locations around the house $(p<0.05)$. They also reported a significant reduction in the number of high-fat foods in their homes $(p<0.001)$ from baseline to post-treatment; however, they did not report a significant change in low-fat food availability $(p>0.05)$ over this time period. When examining changes in food storage and availability in the race-region groups, there were no significant differences between groups in self-reported changes in food storage practices or low-fat food availability. However, there was a significant difference in the selfreported changes in high-fat food availability in the homes of Arkansas African Americans, Arkansas white participants, and Vermont white participants. Both Arkansas African Americans and Arkansas white participants reported significantly greater reductions in the mean number high-fat food items available in their home post-treatment compared to Vermont white participants (with no significant difference between Arkansas African Americans and Arkansas white participants). To account for group differences in weight change, these analyses regarding changes in the food environment variables were repeated using an ANCOVA to adjust for difference in weight change; similar results were found, so unadjusted values are presented in Table 2. However, there were no significant associations observed between pre- to post-treatment weight loss and change in any of the home food environment measures over this period.

\section{Discussion}

Consistent with treatment recommendations to reduce fat intake and remove food cues, participants completing a 6-month behavioral weight loss program reported reducing the availability of high-fat foods in their homes and storing fewer foods in visible locations. There were no significant changes in the number of low-fat foods they reported available in their homes. Changes in highfat food availability in the home found in the current study were similar in magnitude to those reported in previous research using the same measure [10]. In the two available studies that similarly examined changes in availability $[10,11]$, a significant reduction in the 
Table 2 6-month Changes in Weight and the Home Food Environment (Mean \pm SD)

\begin{tabular}{|c|c|c|c|c|c|}
\hline & $\begin{array}{l}\text { Overall } \\
\mathrm{N}=90\end{array}$ & $\begin{array}{r}\begin{array}{r}\text { Vermont White } \\
\text { participants } \\
\mathrm{N}=44\end{array} \\
\end{array}$ & $\begin{array}{r}\begin{array}{r}\text { Arkansas White } \\
\text { participants } \\
\mathrm{N}=21\end{array} \\
\end{array}$ & $\begin{array}{r}\text { Arkansas African } \\
\text { American } \\
\mathrm{N}=25 \\
\end{array}$ & p-value \\
\hline Weight Change (kg) & $-6.5 \pm 6.2$ & $-8.3 \pm 6.8$ & $-6.2 \pm 6.0$ & $-3.6 \pm 4.1$ & $p<0.01$ \\
\hline Food Storage Change (FSQ food categories) & $-0.5 \pm 2.3$ & $-0.8 \pm 2.0$ & $-0.2 \pm 2.6$ & $-0.3 \pm 2.6$ & $p>0.05$ \\
\hline Low-Fat Foods Change (HFI food categories) & $-0.06 \pm 1.7$ & $-0.1 \pm 1.4$ & $-0.05 \pm 1.7$ & $0.04 \pm 2.1$ & $p>0.05$ \\
\hline High-Fat Foods Change ( $\mathrm{HFl}^{\mathrm{b}}$ food categories) & $-1.1 \pm 2.1$ & $-0.5 \pm 1.3$ & $-1.8 \pm 2.6$ & $-1.8 \pm 2.4$ & $p<0.01$ \\
\hline
\end{tabular}

${ }^{\mathrm{a}}$ Food Storage Questionnaire; ${ }^{\mathrm{b}}$ Household Food Inventory

availability of high-fat foods was also reported among participants in behavioral weight control programs (mean decrease of approximately 0.8 high-fat foods in both studies). In contrast to one of these previous studies [10], home food environment changes were not associated with weight changes in the current study. A significant correlation between changes in food availability and weight loss was reported over the 12-month period they studied [10]. It may be that home food environment changes require a longer period of time to influence weight loss than the 6 month period examined in the current study or the 8-week period examined in Gorin and colleagues in their earlier study [11]. On the other hand, a greater magnitude of change to the home environment, as was demonstrated when home grocery delivery was provided in the earlier Gorin et al. study [11], may be required to influence weight loss. Alternatively, the absence of a correspondence between selfreported changes in home food environment and weight change may reflect social desirability (i.e., a reporting bias). All participants in the study were in an intervention that counseled reductions in high-fat foods; therefore, some biases toward reporting decreased high-fat foods in the house might be expected. However, the lack of evidence of changes in the presence of low-fat foods in the home offers some evidence that the impact of a social desirability bias was modest since participants were also counseled to increase their consumption of low-fat, low-calorie foods and a similar effect would therefore have been expected with this variable.

The assessment of home food environment clearly warrants further examination in the context of supporting behavioral weight control efforts. Such research efforts would likely benefit from refined methods to measure the home food environment since current measures are fairly limited and fail to reflect the complicated, multi-factorial nature of the overall home food environment. This concern has been raised about measures of the built environment in general [1] and likely applies to the home food environment in particular. There are likely other crucial factors in the home food environment that may be associated with weight loss which are not captured in the currently available assessment methods [32]. Indeed, it may be important to take a step back and actively work on developing and evaluating standardized measures tailored to evaluating the home food environment prior to undertaking further research in the arena of weight management and home food environment. At this point, the lack of standardized home food availability measures and methodology limits the ability to compare research on home food environments [4-8,10,11,32].

Continued research exploring race/ethnicity and regional elements of the home food environment associated with weight management offers potential for significantly enhancing the understanding of obesity development and treatment. Differences in environmental factors may be contributing to observed differences in the prevalence of obesity $[16,17,33]$ and in obesity treatment outcomes [12-15]. It may be important to take a broader approach to the study of the home environment, as food intake and household food availability are influenced by other spheres including the food environment of the community [3].

A greater understanding racial/ethnic and regional differences in food availability in the home would be advantageous given that studies suggest that household availability may impact obesity prevalence and food consumption for multiple household members [10,34]. Furthermore, modifications to the micro-level food environment (i.e., the home) may be more feasible for individuals interested in addressing obesity rather than re-structuring the larger macro-level food environment (i.e., restaurants, supermarkets). The potential for enhancing the success of behavioral weight control approaches by more directly and robustly targeting modifications to the household food environment is intriguing and worthy of further exploration as it offers a promising direction for refining available obesity treatment methods. Thus, a greater focus on the micro-level food environments may be useful for both obesity treatment and understanding patterns of obesity prevalence.

Some researchers have suggested that cultural factors play an important and often ignored role in the development of obesity [35], and the current study would suggest that regional factors might also be considered. The 
overlap between the cultural factors that characterize the southern region of the United States and those that are common among African American groups has been noted [36,37]. Future considerations of cultural factors associated with obesity might benefit from attention to meaningful regional variations in the cultural meanings and salience of home food environment.

This study has some limitations, including the small sample size, the limited regional representation and the focus on individuals who are engaged in a weight control program. Further, there was racial diversity in only one research center, precluding analyses of a true interaction between race and region. In addition, the lack of information on household composition precluded examining whether the number of individuals in the home made a difference in the home food environment or in the ability to change the home environment as part of a behavioral weight control program. However, the findings are suggestive of potentially important environmental factors that may be salient for understanding the higher dietary fat intake among southerners $[18,19]$ as well as the higher rates of obesity in the south $[16,17]$ and among African Americans [33].

\section{Conclusions}

This study illustrated the largely self-initiated changes in the home food environment of participants enrolled in a 6-month behavioral weight control study. While this study did not demonstrate associations between weight loss and home food environment changes, interesting regional differences in the home food environment did emerge. The role of the home food environment in these regional and racial weight and related health disparities needs further research, as do the possibilities for designing more sensitive measures of the home food environment and methods of modifying this micro-level environment to reduce obesity in these high risk populations.

\section{Acknowledgements}

This research was supported by the NIH grant DK056746

\section{Author details}

${ }^{1}$ Fay W. Boozman College of Public Health, University of Arkansas for Medical Sciences, Little Rock, AR, USA. ²Department of Nutrition and Food Sciences, University of Vermont, Burlington, VT, USA.

\section{Authors' contributions}

DSW and JHB obtained the finances for this study and developed and executed the overall study, while RAK oversaw the implementation of the home environment inventories. DSW advised on the conceptions of data collection and analyses. RAK performed the analyses. RAK wrote the drafts of the paper, and JHB and DSW provided critical feedback on drafts. All authors have seen and approved of the version to be published.

\section{Competing interests}

The authors declare that they have no competing interests
Received: 28 January 2010 Accepted: 24 September 2010

Published: 24 September 2010

\section{References}

1. Papas MA, Alberg AJ, Ewing R, Helzlsouer KJ, Gary TL, Klassen AC: The built environment and obesity. Epidemiol Rev 2007, 29:129-143.

2. McKinnon RA, Reedy J, Handy SL, Rogers AB: Measuring the food and physical activity environments: shaping the research agenda. Am J Prev Med 2009, 36:S81-S85.

3. Bryant M, Stevens J: Measurement of food availability in the home. Nutr Rev 2006, 64:67-76

4. Hanson NI, Neumark-Sztainer D, Eisenberg ME, Story M, Wall M: Associations between parental report of the home food environment and adolescent intakes of fruits, vegetables, and dairy foods. Pub Health Nutr 2005, 8:77-85.

5. Patterson RE, Kristal AR, Shannon J, Hunt JR, White E: Using a brief household food inventory as an environmental indicator of individual dietary practices. Am J Public Health 1997, 87:272-275.

6. Neumark-Sztainer D, Wall M, Perry C, Story M: Correlates of fruit and vegetable intake among adolescents: Findings from Project EAT. Prev Med 2003, 37:198-208.

7. Zabinski MF, Daly T, Norman GJ, Rupp JW, Calfas KJ, Sallis JF, Patrick K: Psychosocial correlates of fruit, vegetable, and dietary fat intake among adolescent boys and girls. J Am Diet Assoc 2006, 106:814-821.

8. Raynor HA, Polley BA, Wing RR, Jeffery RW: Is dietary fat intake related to liking or household availability of high- and low-fat foods? Obesity Res 2004, 12:816-823.

9. Nielsen SJ, Siega-Riz AM, Popkin BM: Trends in energy intake in U.S. between 1977 and 1996: Similar shifts seen across age groups. Obesity 2002, 10:370-378.

10. Gorin AA, Wing RR, Fava JL, Jakicic JM, Jeffery R, West DS, Brelje K, DiLillo VG: Weight loss treatment influences untreated spouses and the home environment: evidence of a ripple effect. Int J Obes 2008, 32:1678-1684.

11. Gorin AA, Raynor HA, Niemeier HM, Wing RR: Home grocery delivery improves the household food environments of behavioral weight loss participants: Results of an 8-week pilot study. Int J Behav Nutr Phys Act 2007, 4:58-63.

12. West DS, Prewitt TE, Bursac Z, Felix HC: Weight loss of Black, White, and Hispanic men and women in the Diabetes Prevention Program (DPP). Obesity 2008, 16:1413-1420.

13. Kumanyika SK, Obarzanek E, Stevens VJ, Hebert P, Whelton P: Weight-loss experience of black and white participants in NHLBI-sponsored clinical trials. Am J of Clin Nutr 1991, 53:S1631-S1638.

14. Kumanyika S, Espeland M, Bahnson J, Bottom J, Charleston J, Foman S, Wilson A, Whelton P, for the Tone Cooperative Research Group: Ethnic comparison of weight loss in the Trial of Nonpharmacologic Interventions in the Elderly. Obesity Res 2002, 10:96-106.

15. Svetkey LP, Erlinger TP, Vollmer WM, Feldstein A, Cooper LS, Appel LJ, Ard JD, Elmer PJ, Harsha D, Stevens VJ: Effect of lifestyle modifications on blood pressure by race, sex, hypertension status and age. J Hum Hypertens 2005, 19:21-31.

16. Wang Y, Beydoun MA: The obesity epidemic in the United State-gender, age, socioeconomic, racial/ethnic, and geographic characteristics: a systematic review and meta-regression analysis. Epidemiol Rev 2007 29:6-28.

17. Singh GK, Kogan MD, van Dyck PC: A multilevel analysis of state and regional disparities in childhood and adolescent obesity in the United States. J Community Health 2008, 33:90-102.

18. Thompson FE, Midthune D, Subar AF, McNeel T, Berrigan D, Kipnis V: Dietary intake estimates in the National Health Interview Survey, 2000: methodology, results, and interpretation. J Am Diet Assoc 2005, 105:352-363.

19. Greenberg MR, Schneider D, Northridge ME, Ganz ML: Region of birth and Black diets: The Harlem Household Survey. Am J Public Health 1998, 88:1199-1202.

20. Pascale RW, Wing RR, Butler BA, Mullen M, Bononi P: Effects of a behavioral weight loss program stressing calorie restriction versus calorie plus fat restriction in obese individuals with NIDDM or a family history of diabetes. Diabetes Care 1995, 18:1241-1248. 
21. Schlundt DG, Hill JO, Pope-Cordle J, Arnold D, Virts KL, Katahn M: Randomized evaluation of a low-fat ad libitum carbohydrate diet for weight reduction. Int J Obes Relat Metab Disord 1993, 17:623-629.

22. Baker EA, Schootman M, Barnidge E, Kelly C: The role of race and poverty in access to foods that enable individuals to adhere to dietary guidelines. Prev Chronic Dis 2006, 3:1-11.

23. Hosler AS, Varadarajulu D, Ronsani AE, Fredrick BL, Fischer BD: Low-fat milk and high-fiber bread availability in food stores in urban and rural communities. J Public Health Manag Pract 2006, 12:556-562.

24. Franco M, Diez Roux AV, Glass TA, Caballero B, Brancati FL: Neighborhood characteristics and availability of healthy foods in Baltimore. Am J Prev Med 2008, 35:561-567.

25. Liese $A D$, Weis KE, Pluto $D$, Smith E, Lawson A: Food store types, availability and cost of foods in a rural environment. J Am Diet Assoc 2007, 107:1916-1923.

26. Look AHEAD research group: Reduction in weight and cardiovascular disease risk factors in individuals with type 2 diabetes. Diabetes Care 2007, 30:1374-1383.

27. Subak LL, Wing R, West DS, Franklin F, Vittinghoff E, Creasman JM, Richter $\mathrm{HE}$, Myers $\mathrm{D}$, Burgio $\mathrm{KL}$, Gorin $\mathrm{AA}$, et al: Weight loss to treat urinary incontinence in overweight and obese women. N Engl J Med 2009, 360:481-490

28. Harvey-Berino J, Pintauro S, Buzzell P, Gold EC: Effect of internet support on the long-term maintenance of weight loss. Obesity Res 2004, 12:320-329.

29. Diabetes Prevention Program Research Group: The Diabetes Prevention Program (DPP): description of lifestyle intervention. Diabetes Care 2002, 25:2165-2171.

30. Harvey-Berino J, West D, Krukowski R, Prewitt E, VanBiervliet A, Ashikaga T, Skelly J: Internet delivered behavioral obesity treatment. Prev Med 2010, 51:123-128.

31. Ware JH: Interpreting incomplete data in studies of diet and weight loss. N Engl J Med 2003, 348:2136-2137.

32. Fulkerson J, Nelson M, Lytle L, Moe S, Heitzler C, Pasch K: The validation of a home food inventory. Int J Behav Nutr Phys Act 2008, 5:55.

33. Ogden $\mathrm{CL}$, Carroll MD, Curtin LR, McDowell MA, Tabak CJ, Flegal KM: Prevalence of overweight and obesity in the United States, 1999-2004. J Am Med Assoc 2006, 295:1549-1555.

34. Kratt P, Reynolds K, Shewchuk R: The role of availability as a moderator of family fruit and vegetable consumption. Health Educ Behav 2000, 27:471-482.

35. Kumanyika SK, Whitt-Glover MC, Gary TL, Prewitt TE, Odoms-Young AM, Banks-Wallace J, Beech BM, Halbert CH, Karanja N, Lancaster KJ, SamuelHodge CD: Expanding the obesity research paradigm to research African American communities. Prev Chronic Dis 2007, 4:1-22.

36. Latshaw BA: Food for Thought. Southern Cultures 2009, 15:106-128.

37. Keita A, Casazza K, Cardel M, Fernandez JR: Adherence to southern culture increases obesity risk. The Obesity Society; Washington, DC 2009, S225.

doi:10.1186/1479-5868-7-69

Cite this article as: Krukowski et al:: Differences in home food availability of high- and low-fat foods after a behavioral weight control program are regional not racial. International Journal of Behavioral Nutrition and Physical Activity 2010 7:69.

\section{Submit your next manuscript to BioMed Central and take full advantage of:}

- Convenient online submission

- Thorough peer review

- No space constraints or color figure charges

- Immediate publication on acceptance

- Inclusion in PubMed, CAS, Scopus and Google Scholar

- Research which is freely available for redistribution

Submit your manuscript at www.biomedcentral.com/submit 